\title{
Hypofractionated versus Conventionally Fractionated Radiotherapy in Post-Mastectomy Breast Cancer Patients
}

\author{
Fatma M. F. Akl ${ }^{1 *}$, Ashraf Khater ${ }^{2}$ \\ ${ }^{1}$ Clinical Oncology \& Nuclear Medicine Department, Mansoura University, Egypt \\ ${ }^{2}$ Surgical Oncology Department, Oncology Center, Mansoura University, Egypt \\ Email: ^fatmaakl@yahoo.com
}

How to cite this paper: Akl, F.M.F. and Khater, A. (2018) Hypofractionated versus Conventionally Fractionated Radiotherapy in Post-Mastectomy Breast Cancer Patients. Journal of Cancer Therapy, 9, 941-954. https://doi.org/10.4236/jct.2018.911078

Received: November 1, 2018 Accepted: November 25, 2018 Published: November 29, 2018

Copyright $(9) 2018$ by authors and Scientific Research Publishing Inc. This work is licensed under the Creative Commons Attribution International License (CC BY 4.0).

http://creativecommons.org/licenses/by/4.0/

\begin{abstract}
Background \& Objective: Hypofractionation has been used in curative setting in breast conservative surgery, but still no adequate information about its application in the adjuvant setting after mastectomy in breast cancer patients. The aim of this trial was to assess the efficacy and toxicity of hypofractionation radiotherapy (40 Gy in 15 fractions) in post mastectomy breast cancer patients and to compare these results with those of post mastectomy patients treated retrospectively by conventional radiotherapy (50 Gy in 25 fractions) as regard overall survival (OS), disease free survival (DFS), locoregional disease free survival (LDFS), and toxicities. Patients \& Methods: One hundred post mastectomy breast cancer patients were included into this study, they were divided into 2 groups, the 1 st included 50 patients treated prospectively with hypofractionated radiotherapy regimen ( $40 \mathrm{~Gy}$ in 15 fractions), and the 2nd (control group) included 50 patients treated retrospectively with conventionally fractionated radiotherapy regimen ( $50 \mathrm{~Gy}$ in 25 fractions). Results: The 2 year overall survival were $96 \% \& 94 \%$ respectively $(\mathrm{p}=0.7)$, while the disease free survival were $91 \% \& 89.8 \%$, respectively $(\mathrm{p}=0.9)$, and the LDFS were $95.8 \%$ \& $93.3 \%$, respectively $(\mathrm{p}=0.9), \mathrm{G} 1$ acute dermatitis was observed in $22(44 \%) \& 25(50 \%)$ patients in group I \& II respectively, G2 in $8(16 \%)$ \& $10(20 \%)$ patients respectively, no G4 skin toxicity was detected. Radiation pneumonitis was observed in 2 patients (4\%) only in group II. Conclusion: post-mastectomy hypofractionated radiation therapy achieved comparable survival and toxicity to the conventionally fractionated radiotherapy with the advantage of reducing overall treatment time, treatment burden $\&$ cost.
\end{abstract}

\section{Keywords}

Breast Cancer, Adjuvant Radiotherapy, Hypofractionation, Conventional Fractionation 


\section{Introduction \& Objective}

Breast cancer is the most commonly diagnosed cancer worldwide and it is the leading cause of cancer death in women. In 2016, 249,260 women have been diagnosed with breast cancer in the United States of America with 40,890 deaths [1].

Radiation therapy is a part of treatment in all breast conserving surgeries and for a large percentage of breast cancer patients after mastectomy, and it has been identified to decrease the local recurrence by $70 \%$ [2].

Also, it has a positive effect on overall survival, specifically in patients with a high incidence of loco-regional recurrence [3].

In spite of the established role of adjuvant radiotherapy, much debate remains about the ideal radiotherapy regimen to use. Several alternative fractionation regimens have recently been assessed and compared with the standard fractionation schedule (25 fractions, 2 Gy each/5 weeks) [4].

The alternative fractionation schedule that has received the most attention is hypofractionation, in which radiation is delivered using a lower number of fractions of more than 2 Gy each ( $40 \mathrm{~Gy} / 15$ daily fractions of 2.67 Gy to the whole breast, with a boost dose of $15 \mathrm{~Gy}$ in $3 \mathrm{~Gy}$ fractions) [5].

The theoretical advantages of hypofractionation include an improvement in cell killing from the increase in fraction size and a reduction in treatment duration. Furthermore, shortening the treatment duration means that more patients can be treated with a limited number of machines, a concern that arises in many countries in which access to radiation therapy is limited [6].

Many trials have confirmed that, hypofractionated radiotherapy schedules are equivalent to conventionally fractionated radiation of 50 Gy in 25 sessions irrespective of stage or breast surgery [5] [7], hypofractionated whole breast irradiation is a preferred option in United States of America, Canada and United kingdom because of its low cost and geographical convenience [8].

Due to these established data, hypofractionation has been used in curative setting in breast conservative surgery, but still no adequate information about its application in the adjuvant setting after mastectomy in breast cancer patients.

At our department, hypofractionated radiotherapy was applied first in late 2013 as an adjuvant treatment after breast conserving surgery in node negative patients, and since then, it was used. Currently, almost all patients needing adjuvant radiotherapy to the chest wall receive hypofractionated regimen (40 Gy in 15 fractions).

The aim of this trial was to assess the efficacy and toxicity of hypofractionation radiotherapy (40 Gy in 15 fractions) in post mastectomy breast cancer patients and to compare these results with those of post mastectomy patients treated retrospectively by conventional radiotherapy (50 Gy in 25 fractions) as regard overall, disease free and loco-regional disease free survival, and toxicities.

\section{Patients and Methods}

After acceptance of the Mansoura Faculty of Medicine, institutional research 
board MFM IRB, 100 female patients with breast cancer treated at the Clinical Oncology \& Nuclear Medicine department in collaboration with the Oncosurgery department, Oncology center, Mansoura University, were included into this study in the period between January, 2015 till January, 2017.

All patients had signed an informed consent forms before enrollment.

Inclusion criteria includes: a pathological proof of breast cancer and surgical intervention by modified radical mastectomy (MRM) and axillary dissection. Radiation started after completion of the last cycle of adjuvant chemotherapy. Exclusion criteria included those who have a skin disease that may interfere with radiation toxicity.

Patients were divided into 2 groups: the $1^{\text {st }}$ included 50 patients who were treated prospectively with mastectomy in the Oncosurgery department, Oncology center, Mansoura university, then received post operative hypofractionated radiotherapy regimen ( $40 \mathrm{~Gy}$ in 15 fractions).

The $2^{\text {nd }}$ (control group) included 50 patients treated retrospectively with mastectomy \& conventional radiotherapy regimen (50 Gy in 25 fractions).

Eligible patients were planned to receive hypofractionation radiotherapy of 40 Gy in 15 sessions in 3 weeks to the ipsilateral chest wall and periclavicular nodal region (hypofractionated group, HFRT, $1^{\text {st }} \mathrm{gp}$ ).

Control group $\left(2^{\text {nd }}\right)$ involved postmastectomy breast cancer patients who received retrospectively conventionally fractionated radiation of $50 \mathrm{~Gy} / 25$ sessions over 5 weeks to the chest wall and periclavicular nodal region (conventional group, CFRT) in the period between January 2013 to January 2014.

\subsection{Radiation Therapy Techniques}

Patients were planned in the supine position over a breast board with arms directed cranially using computerized tomography (CT) simulation, with CT slices of $5 \mathrm{~mm}$ thick. Standard two tangential fields were used to treat the breast; an additional supraclavicular field was added if lymph nodes treatment was indicated. All patients were planned by 3D-Conformal radiotherapy (3D-CRT) with ELEKTA Linear Accelerator, and precise treatment planning software.

HFRT group were given $4000 \mathrm{cGy} / 15$ fractions/3 weeks at $267 \mathrm{cGy}$ per fraction, 5 day per week.

The control CFRT group were given 5000 cGy/25 fractions/5 weeks at 200 cGy per fraction, 5 days per week.

The photon energy used in both groups was either $6 \mathrm{MV}$ or $15 \mathrm{MV}$.

\subsection{Radiation Toxicity and Its Grading}

During the radiation therapy schedule; patients were weekly observed for the acute radiation reactions and it was reported and graded according to the Radiation Therapy Oncology Group (RTOG) toxicity criteria.

After ending radiation schedule, patients were followed up every 2 weeks for one month and then, every month to a minimum of 6-months for late reactions, 
shoulder movements restriction, and brachial plexopathy and radiation pneumonitis.

\subsection{Statistical Analysis}

Data was analyzed by SPSS, program statistical package for social science version 16.

To test the normality of data distribution, K-S (Kolmogorov-Smirnov) test was done, only significant data revealed to be nonparametric. However all tested data revealed to be parametric. The description of the data done in form of mean (+/-) SD for quantitative data, while frequency \& proportion for qualitative data. The analysis of the data was done to test statistical significant difference between groups. For quantitative data, student $t$-test was used to compare between two groups. Chi square test was used for qualitative data.

\section{Results}

The patients characteristics were matched in between the two groups. The median age (range) in the $1^{\text {st }} \& 2^{\text {nd }}$ groups were: $47(31-64)$ and 50 (34 - 68) years; Menopausal status: Premenopausal-25/50 (50\%) vs. 21/50 (42\%), postmenopausal-19/50 (38\%) vs. 22/50 (44\%) (Table 1).

The histopathologic type was infiltrating ductal carcinoma in all the patients in both groups. The primary tumor site in Group I and II was: Right breast-19/50 (38\%) vs. $21 / 50$ (42\%), Left breast-31/50 (62\%) vs. 29/50 (58\%). Estrogen receptor status in the $1^{\text {st }} \& 2^{\text {nd }}$ groups were: Positive $39 / 50$ (78\%) vs. $36 / 50(72 \%)$, Negative $11 / 50$ (22\%) vs. $14 / 50$ (28\%), respectively, while progesterone receptor status the in $1^{\text {st }} \& 2^{\text {nd }}$ groups were: Positive $34 / 50$ (68\%) vs. $31 / 50$ (62\%), Negative-16/50 (32\%) vs. 19/50 (38\%), respectively (Table 1 ).

All the patients ended their adjuvant radiotherapy schedule. All patients tolerated radiation treatment well, with no radiotherapy interruption because of toxicity in the $1^{\text {st }}$ group, while in the $2^{\text {nd }}$ group, treatment was interrupted for 3 patients (for 4 - 6 days) because of G III skin toxicity.

The median duration of radiation interruption because of patient inconvenience \& machine technical issues were $3 \& 5$ days in the $1^{\text {st }} \& 2^{\text {nd }}$ groups, respectively.

The median follow up was 22 (16 - 24 months).

\subsection{Acute Radiation Toxicity}

As regard skin reaction, G1 was observed in $22(44 \%) \& 25$ (50\%) patients in group I \& II respectively, G2 in $8(16 \%)$ \& 10 (20\%) patients respectively, no G4 skin toxicity was detected. Radiation pneumonitis was observed in 2 patients (4\%) only in group II, which developed 1.5 - 2 months after the end of radiotherapy (Table 2).

Grade I dysphagia was observed in $21(42 \%) \& 18(36 \%)$ cases in group I \& II respectively, which improved by symptomatic treatment. G1 lymphedema was 
Table 1. Patients' characteristics.

\begin{tabular}{|c|c|c|c|}
\hline Characteristics & HFRT group $(n=50)$ & CFRT group $(n=50)$ & $P$ value \\
\hline \multicolumn{4}{|l|}{ Age (years) } \\
\hline Median & 47 & 50 & \multirow[b]{2}{*}{0.9} \\
\hline Range & $31-64$ & $34-68$ & \\
\hline \multicolumn{4}{|l|}{ Laterality side } \\
\hline Left & $31(62 \%)$ & $29(58 \%)$ & 0.7 \\
\hline \multicolumn{4}{|l|}{ stage } \\
\hline IIa & $6(12 \%)$ & $8(16 \%)$ & \multirow{5}{*}{0.8} \\
\hline IIb & $13(26 \%)$ & $16(32 \%)$ & \\
\hline IIIa & $27(54 \%)$ & $21(42 \%)$ & \\
\hline IIIb & $2(4 \%)$ & $3(6 \%)$ & \\
\hline IIIc & $2(4 \%)$ & $2(4 \%)$ & \\
\hline \multicolumn{4}{|l|}{ Grade } \\
\hline II & $39(78 \%)$ & $41(82 \%)$ & \multirow{2}{*}{0.6} \\
\hline III & $11(22 \%)$ & $9(18 \%)$ & \\
\hline \multicolumn{4}{|l|}{ Histological type } \\
\hline IDC & $50(100 \%)$ & $50(100 \%)$ & \\
\hline \multicolumn{4}{|l|}{ Hormonal status: } \\
\hline \multicolumn{4}{|l|}{ ER: } \\
\hline$+\mathrm{ve}$ & $39(78 \%)$ & $36(72 \%)$ & \multirow[b]{2}{*}{0.5} \\
\hline$-\mathrm{ve}$ & $11(22 \%)$ & $14(28 \%)$ & \\
\hline \multicolumn{4}{|l|}{ PR: } \\
\hline$+\mathrm{ve}$ & $34(68 \%)$ & $31(62 \%)$ & \multirow[b]{2}{*}{0.6} \\
\hline$-\mathrm{ve}$ & $16(32 \%)$ & $19(38 \%)$ & \\
\hline \multicolumn{4}{|l|}{ HER-2: } \\
\hline$+\mathrm{ve}$ & $21(42 \%)$ & $15(30 \%)$ & \multirow{3}{*}{0.06} \\
\hline$-\mathrm{ve}$ & $24(48 \%)$ & $21(42 \%)$ & \\
\hline Not determined & $5(10 \%)$ & $14(28 \%)$ & \\
\hline \multicolumn{4}{|l|}{ Menopausal status: } \\
\hline Premenopausal & $25(50 \%)$ & $21(42 \%)$ & \\
\hline perimenopausal & $6(12 \%)$ & $7(14 \%)$ & 0.7 \\
\hline postmenopausal & $19(38 \%)$ & $22(44 \%)$ & \\
\hline
\end{tabular}

seen in $16(32 \%) \& 19(38 \%)$ cases, G2 in 7 (14\%) \& $9(18 \%)$ patients, respectively. No cases showed injury of the brachial plexus (Table 2). 
Table 2. Treatment-related acute toxicity.

\begin{tabular}{ccccccccccc}
\hline \multirow{3}{*}{ Toxicities } & \multicolumn{7}{c}{ HFRT } & \multicolumn{7}{c}{ CFRT } & \multirow{2}{*}{ P value } \\
\cline { 2 - 7 } & I & II & III & IV & I & II & III & IV & \\
\hline skin & $22(44 \%)$ & $8(16 \%)$ & 0 & 0 & $25(50 \%)$ & $10(20 \%)$ & $3(6 \%)$ & 0 & 0.3 \\
dysphagia & $21(42 \%)$ & $9(18 \%)$ & $1(2 \%)$ & 0 & $18(36 \%)$ & $7(14 \%)$ & 0 & 0 & 0.7 \\
$\begin{array}{c}\text { radiation } \\
\text { pnemonitis }\end{array}$ & 0 & 0 & 0 & 0 & $2(4 \%)$ & 0 & 0 & 0 & 0.9 \\
$\begin{array}{c}\text { Lymphedema } \\
\text { Brachial }\end{array}$ & $16(32 \%)$ & $7(14 \%)$ & 0 & 0 & $19(38 \%)$ & $9(18 \%)$ & 0 & 0 & 0.8 \\
plexopathy & 0 & 0 & 0 & 0 & 0 & 0 & 0 & 0 & \\
\hline
\end{tabular}

\subsection{Late Radiation Toxicity}

Skin \&subcutaneous tissue toxicity were the common side effects in both groups, with most patients of G1 \& 2 toxicity, no G 3 or 4 toxicity. Grade 1was detected in $(4 / 8 \%)$ patients $\&$ in $(3 / 6 \%)$ patients in the $1^{\text {st }} \& 2^{\text {nd }}$ groups respectively, while grade 2 was expressed in 2 patients in group II only \& formed $4 \%$.

\subsection{Survival}

As regard survival in the HFRT \& CFRT groups, the 2 year overall survival were $96 \% \& 94 \%$ respectively $(\mathrm{p}=0.7)$ (Figure 1 ), while the disease free survival were $91 \%$ \& $89.8 \%$, respectively $(\mathrm{p}=0.9)$ (Figure 2 ), and the LDFS were $95.8 \% \&$ $93.3 \%$, respectively $(\mathrm{p}=0.9)$ (Figure 3 ).

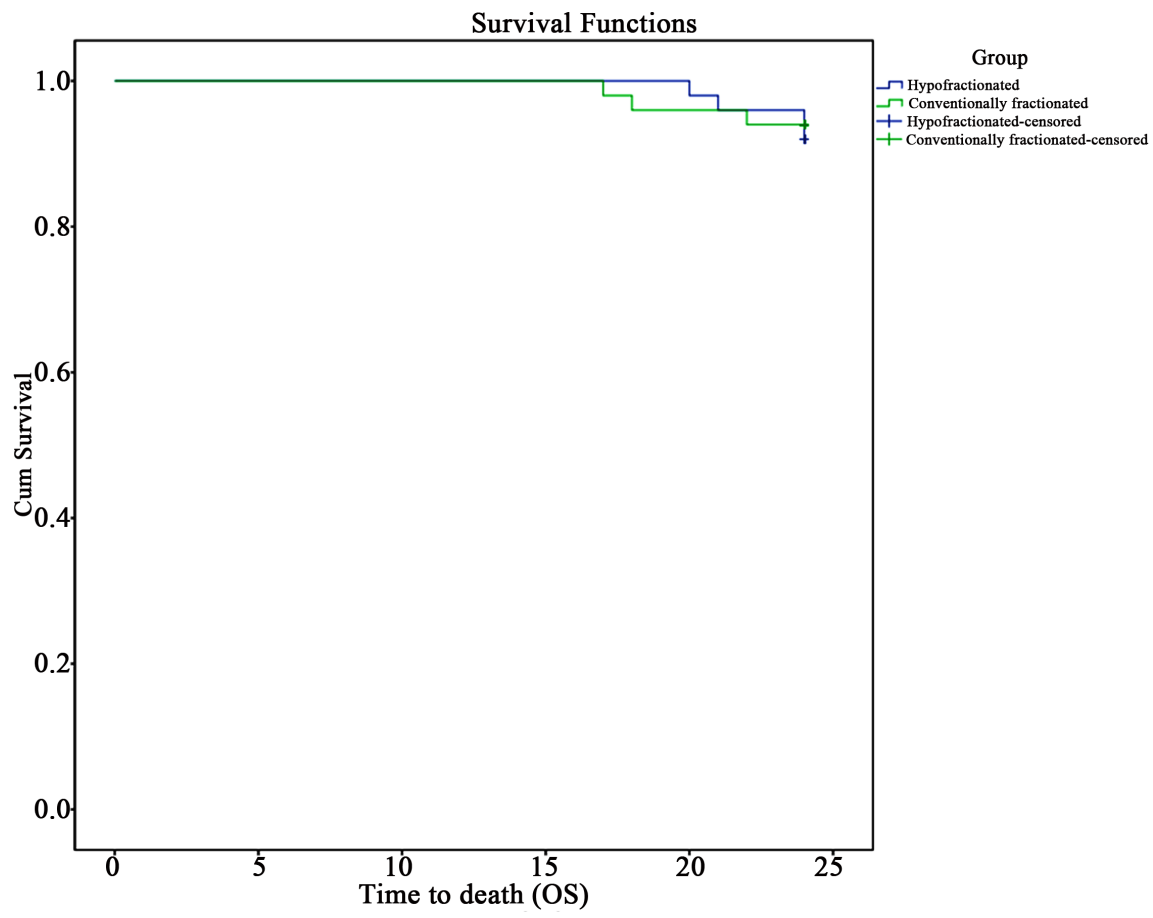

Figure 1. The overall survival of the 2 treatment groups. 


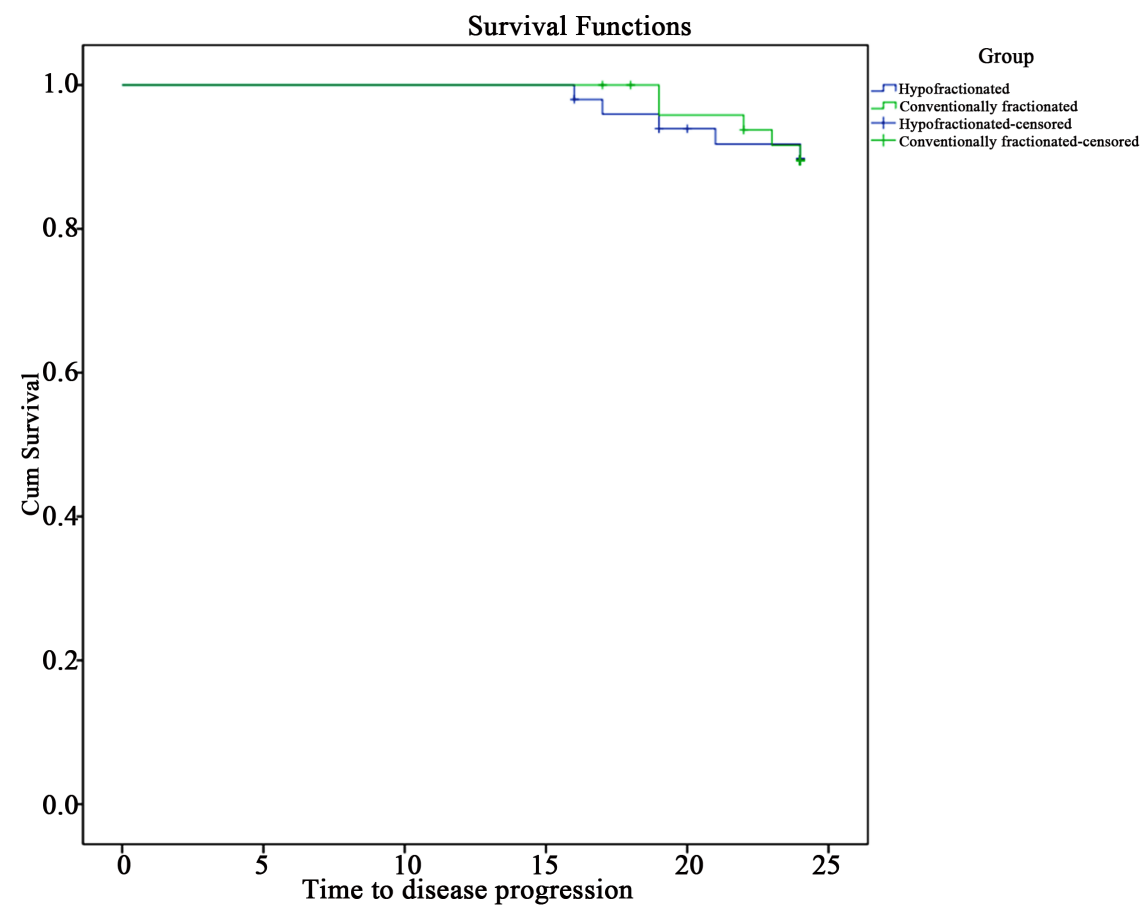

Figure 2. The disease free survival of the 2 treatment groups.

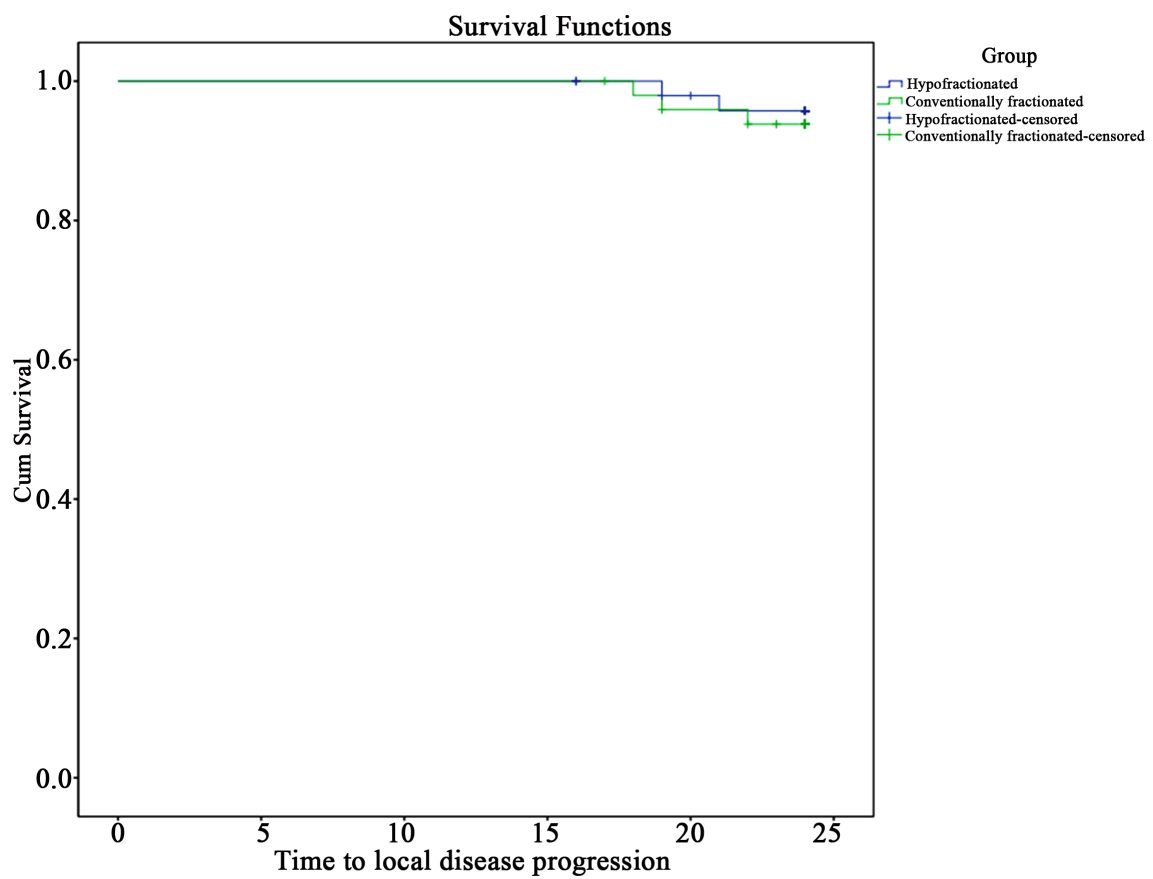

Figure 3. Local disease free survival.

\section{Discussion}

In breast cancer, radiotherapy is given to all patients after breast conservation and if indicated for patients after mastectomy [9].

Adjuvant radiation therapy eradicates any tumor deposits remaining following surgery, which reduces locoregional recurrence (LRR) and improves breast 
cancer-specific and overall survivals [3].

Conventional adjuvant radiotherapy to chest wall after modified radical mastectomy is 25 fractions within 5 weeks. Hypo fractionated radiotherapy uses a smaller number of fractions and larger doses per fraction more than 2 Gy [4] [7].

Different hypofractionated schedules had been identified, one of the commonest hypofractionation protocols is $40 \mathrm{~Gy} / 15$ fractions/3 weeks, Therefore, this schedule leads to decrease in treatment time from 5 weeks to 3 weeks with nearly the same local control and cosmetic rate, also, it has more convenient and has financial advantages as it has lower costs due to fewer travels to treatment centers compared to conventional radiotherapy [10].

Also, breast cancer radiation therapy is responsible for $25 \%-30 \%$ of all radiotherapy treatment burden. The hypofractionation regimen offers more efficient use of resources, so that more patients can be treated with the existing machines and personnel [11].

The results of numerous randomized trials which compared conventional fractioned radiotherapy (50 Gy in 5 weeks/25 fractions) for patients with breast cancer with hypo fractionated radiotherapy (39 - 42.9 Gy/13 - 16 fractions in 3 5 weeks) indicated that hypofractionation can be safely delivered to most patients [12]. So, the use of hypofractionation has gained increasing popularity as a post operative treatment following breast conservation [4] [7] [13] [14], but the data on post-mastectomy hypofractionation is still limited.

At our department, hypofractionation was first adopted as adjuvant treatment after breast conserving surgery in 2013, and then it has been increasingly used since then. Currently, almost all patients requiring adjuvant radiotherapy receive hypofractionation schedule ( $40 \mathrm{~Gy} / 15$ fractions/3 weeks). This trial was done to assess the efficacy and toxicity of hypofractionation schedule (40 Gy in 15 fractions) in post mastectomy breast cancer patients and to compare these results with those of post mastectomy patients treated retrospectively by conventional radiotherapy (50 Gy in 25 fractions) as regard OS, DFS and loco-regional control, and treatment toxicities.

In the current study, the 2 year overall survival were $96 \% \& 94 \%$ respectively $(\mathrm{p}=0.7)$, while the disease free survival were $91 \% \& 89.8 \%$, respectively $(\mathrm{p}=$ $0.9)$, and the LDFS were $95.8 \% \& 93.3 \%$, respectively $(\mathrm{p}=0.9)$. As regard skin reaction, G1 was observed in $22(44 \%) \& 25(50 \%)$ patients in group I \& II respectively, G2 in $8(16 \%) \& 10(20 \%)$ patients respectively, no G4 skin toxicity was detected. Radiation pneumonitis was observed in 2 patients (4\%) only in group II.

Grade I dysphagia was observed in $21(42 \%)$ \& 18 (36\%) cases in group I \& II respectively, which improved by symptomatic treatment. G1 lymphedema was seen in $16(32 \%) \& 19(38 \%)$ cases, G2 in $7(14 \%) \& 9$ (18\%) patients, respectively.

Several randomized trials that have proved equivalent local control and cosmosis between hypofractionation and conventional fractionation schedules [15], [16]. ASTRO guidelines recommended hypofractionation use in early breast 
cancer but they could not accept it as a tumor bed boost [17].

In a study by Ciammella et al. they involved 212 women with early breast cancer underwent conserving surgery. Patients received 40.05 Gy in 15 daily fractions, with boost to the tumor bed of $9 \mathrm{~Gy}$ in 3 consecutive fractions in 55 patients, they detected higher incidence of G I dermatitis, in $79 \%$ of patients and G II in $12 \%$ of patients, in contrast to the results of the $1^{\text {st }}$ group in the current study $(44 \%$ \& $16 \%)$ respectively [18].

There have been 4 large randomized controlled trials evaluating the results of hypofractionated versus conventionally fractionated radiotherapy following breast conservation, Canadian, START A, START B and Royal Marsden Hospital (RMH) [4] [7] [13] [14] [19].

START A trial is a multicenter randomized trial, involved 2236 patients with early breast cancer who received adjuvant hypofractionation schedules with $2 \mathrm{~Gy}$ (45 Gy/25 fractions) versus 3 Gy (39 Gy/13fractions) versus 3.2 Gy (41.6 Gy/13 fractions), the difference in 5 years locoregional relapse rates compared with 50 Gy were $0.2 \%$ after $41.6 \mathrm{~Gy}$ and $0.9 \%$ after 3.9 Gy [7].

Also START B is a randomized trial involved 2215 early breast cancer patients who were given adjuvant radiotherapy by different schedules, $50 \mathrm{~Gy} / 25$ fractions at $2 \mathrm{~Gy}$ in 5 weeks versus $40 \mathrm{~Gy} / 16$ fractions at $2.67 \mathrm{~Gy} / 3$ weeks, locoregional tumor recurrence rates were comparable with slighty superior cosmetic outcome in hypofractionation group [4].

The British Columbia randomized trial of adjuvant radiotherapy after mastectomy included 318 premenopausal women with node-positive disease, who were randomized to receive locoregional RT. Patients received 37.5 Gy in 16 fractions to the chest wall and $35 \mathrm{~Gy}$ in 16 fractions to the regional nodes, patients in the hypofractionated group had a lower incidence of loco-regional relapses $(74 \%$ vs. $90 \%, \mathrm{p}=0.002)$ [20].

Our results are in accordance with Shaltout and Abd El Razek 2012, and Eldeep, et al. 2012, all of them concluded comparable results between the hypofractionated \& conventional radiotherapy as regards, local control \& DFS, which were statistically insignificant [21] [22].

Another retrospective study included breast cancer patients, who were treated by surgery, radiotherapy and adjuvant systemic therapy, radiotherapy was given by two schedules; conventional (162 patients), and hypofractionated (181 patients). The 4 year overall \& disease free survival for the whole group were $86.5 \%$ $\& 83.8 \%$ respectively [23].

A randomized trial involved postmastectomy breast cancer patients who were given 2 radiation schedules: Arm A (45) Arm B (46), $1^{\text {st }}$ arm was given 50 Gy/25 fractions and the 2 nd was given $40 \mathrm{~Gy} / 17$ fractions.

Chest wall recurrence was $5 \%$ versus $9 \%$ ( $p>0.05$ ), axillary lymph node failure $8 \%$ versus $7 \%(p>0.05)$, distant metastasis $25 \%$ versus $28 \%(p>0.05)$, no statistically significant difference in local control and efficacy was observed between the 2 radiation schedules [24].

Forty-seven breast cancer patients (stage T2-4, any N), were randomized into 
2 groups; conventionally fractionated group ( $\mathrm{N}: 22)$, and hypofractionated group $(\mathrm{N}: 25)$. The 4year overall survival for the whole group were $98 \%$ (100\% for CFRT group and $96 \%$ for HFRT group) $(\mathrm{P}=0.37)$. The 4 year DFS for all patients were $87 \%$ ( $81 \%$ and $92 \%$ for CFRT and HFRT groups, respectively) ( $\mathrm{p}=$ 0.47 ), regarding treatment toxicity, grade I skin toxicity were detected in $55 \%$ and $52 \%$ of patients in the HFRT and CFRT groups, respectively, while grade II were $24 \%$ and $9.09 \%$, respectively $(\mathrm{p}=0.18$ ). Grade II radiation pneumonitis were $12 \%$ \& $4.5 \%$ in HFRT and CFRT groups, respectively. These results were comparable to the current study [25].

In a retrospective study from 2004 to 2006, 215 patients were analyzed, $67 \mathrm{pa}-$ tients were treated by conventional fractionated radiotherapy and 148 patients by hypofractionated radiotherapy (2.65 Gy/16 - 18 fractions). The 5 year local recurence free survival was $86.6 \%$ in CRT and $85.8 \%$ in HFRT ( $\mathrm{p}=0.852$ ), the 5 year DFS was $62.7 \%$ and $69.6 \%(\mathrm{p}=0.136)$ in conventional \& hypofractionated groups, respectively. Patients in the hypofractionated radiotherapy had longer 5year OS $(62.7 \%$ and $73.0 \%(\mathrm{p}=0.048)$, with comparable toxicity between the 2 arms [26].

In a study by Singh et al., 216 breast cancer patients were treated with hypofractionated radiotherapy (40 Gy/15 fractions) (study group) versus (50 Gy/25 fractions, control group). Seventeen patients had local recurrence, eight in the hypofractionated group and nine in the control group. The 2 years LRFS was $97.2 \% \& 96.8 \%$ in the study \& control groups, respectively. Late radiation pneumonitis was detected in $3 \% \& 4 \%$ inthe study \& control groups respectively [27].

In a study by Dore et al., 205 postmenopausal breast cancer patients between June 2004 and June 2012 were analyzed, they were treated by hypofractionated radiotherapy (HFRT) whether, after breast conservation (116/57\%) or mastectomy (43/89\%). Three out of 116 (2.6\%) patients and 4/89 (4.5\%) had local relapse after breast conserving surgery and mastectomy, respectively. Five year local recurrence rate was $4.4 \%$. grade III skin toxicity was detected in $(8 / 4.5 \%)$ patients, late fibrosis in $(29 / 14 \%)$ and telangiectasia (16/8\%), with no pulmonary or cardiac toxicities [28].

In a prospective study, 56 patients treated by adjuvant HFRT (42.5 Gy/16 fractions in 3 weeks). Acute dermatitis of grade I, II and III were detected in $75 \%, 16 \%$ and $1.8 \%$, respectively. Radiotherapy was not interrupted for any patient [29].

Two hundred and sixteen breast cancer patients following mastectomy were treated with 2 hypofractionated schedules: $40 \mathrm{~Gy} / 15$ sessions or $42.5 \mathrm{~Gy} / 16$ sessions, $14.8 \%$ developed $\geq$ Grade (Gr) 2 late cardiac toxicity, $10.2 \%$ developed $\geq$ Gr2 late pulmonary toxicity. There were $28.7 \%$ patients who developed $\geq \mathrm{Gr} 2$ lymphedema. Sixty-seven out of 216 patients had symptomatic brachial plexopathy at 5-year follow-up [30].

In a phase II trial by Khan et al., patients with stage II to IIIa breast cancer were treated by postmastectomy hypofractionated radiation, in 15 fractions, they 
stated that it was tolerable and efficient in patients. Acute dermatitis was the commonest (24\%) toxicity, then, fatigue (7.5\%), pain (4.5\%), and lymphedema (4.5\%). Chest wall recurrence was detected in 2 patients (3\%). the 3 year LRFS was $89.2 \%$, while distant recurrence free survival was 00.3 [31].

The current results are consistent with most of mentioned trials.

\section{Conclusion}

Post-mastectomy hypofractionated radiation therapy achieved comparable OS, DFS, LDFS and toxicity to the conventionally fractionated radiotherapy with the advantage of reducing overall treatment time, treatment burden $\&$ cost.

\section{Limitations}

This study is limited by the relatively small number of patients and short follow-up period and the retrospective nature of the control group.

\section{Conflicts of Interest}

The authors declare no conflicts of interest regarding the publication of this paper.

\section{References}

[1] Sigel, R.L., Miller, K.D. and Jemal, A. (2016) Cancer Statistics 2016. CA: A Cancer Journal for Clinicians, 65, 5-29.

[2] Dinshaw, K.A., Sarin, R., Budrukkar, A.N., Shrivasta, S.K., Deshpande, D.D., Chinoy, R.F., Badwe, R. and Hawaldar, R. (2006) Safety and Feasibility of Breast Conserving Therapy in Indian Women: Two Decades of Experience at Tata Memorial Hospital. Journal of Surgical Oncology, 94, 105-113.

https://doi.org/10.1002/jso.20497

[3] Darby, S., McGale, P., Correa, C., Taylor, C., Arriagada, R., Clarke, M., Cutter, D., Davies, C., Ewertz, M., Godwin, J., Gray, R., Pierce, L., Whelan, T., Wang, Y. and Peto, R., Early Breast Cancer Trialists' Collaborative Group (EBCTCG) (2011) Effect of Radiotherapy after Breast-Conserving Surgery on 10-Year Recurrence and 15-Year Breast Cancer Death: Meta-Analysis of Individual Patient Data for 10,801 Women in 17 Randomised Trials. Lancet, 378, 1707-1716.

[4] Bentzen, S.M., Agrawal, R.K., Aird, E.G., Barrett, J.M., Barrett-Lee, P.J., Bliss, J.M., Brown, J., Dewar, J.A., Dobbs, H.J., Haviland, J.S., Hoskin, P.J., Hopwood, P., Lawton, P.A., Magee, B.J., Mills, J., Morgan, D.A., Owen, J.R., Simmons, S., Sumo, G., Sydenham, M.A., Venables, K. and Yarnold, J.R. (2008) The UK Standardisation of Breast Radiotherapy (START) Trial B of Radiotherapy Hypofractionation for Treatment of Early Breast Cancer: A Randomized Trial. Lancet, 371, 1098-1107. https://doi.org/10.1016/S0140-6736(08)60348-7

[5] Whelan, T.J., Kim, D.H. and Sussman, J. (2008) Clinical Experience Using Hypofractionated Radiation Schedules in Breast Cancer. Seminars in Radiation Oncolo$g y, 18,257-264$. https://doi.org/10.1016/j.semradonc.2008.04.008

[6] Fowler, J.F. (1989) The Linear-Quadratic Formula and Progress in Fractionated Radiotherapy. The British Journal of Radiology, 62, 679-694.

https://doi.org/10.1259/0007-1285-62-740-679 
[7] Bentzen, S.M., Agrawal, R.K., Aird, E.G., Barrett, J.M., Barrett-Lee, P.J., Bliss, J.M., Brown, J., Dewar, J.A., Dobbs, H.J., Haviland, J.S., Hoskin, P.J., Hopwood, P., Lawton, P.A., Magee, B.J., Mills, J., Morgan, D.A., Owen, J.R., Simmons, S., Sumo, G., Sydenham, M.A., Venables, K. and Yarnold, J.R. (2008) The UK Standardisation of Breast Radiotherapy (START) Trial A of Radiotherapy Hypofractionation for Treatment of Early Breast Cancer: A Randomized Trial. The Lancet Oncology, 9, 331-341. https://doi.org/10.1016/S1470-2045(08)70077-9

[8] Banu, P.A., Rukhsana, N., Jabber, M.A., Rahman, M. and Malik, S.R. (2015) Hypofractionated Radiotherapy for Post-Operative Breast Cancer Patients at Delta Hospital-An Evaluation of Clinical Experience. Delta Medical College Journal, 3, 4-8.

[9] Bhattacharyya, T., Mahajan, R., Ghoshal, S., Yadav, B.S. and Rai, B. (2015) Hypofractionated Radiotherapy in Carcinoma Breast: What We Have Achieved? Journal of Cancer Research and Therapeutics, 11, 259-263. https://doi.org/10.4103/0973-1482.157342

[10] Taher, A.N., El Baradie, M.M., Essa, H., Zaki, O. and Ezzat, S. (2004) Hypofractionation versus Conventional Fractionation Radiotherapy after Conservative Treatment of Breast Cancer: Early Skin Reactions and Cosmetic Results. Journal of the Egyptian National Cancer Institute, 16, 178-187.

[11] Veronesi, U., Cascinelli, N., Greco, M., Bufalino, R., Morabito, A., Galluzzo, D., Conti, R., De Lellis, R., Delle Donne, V., Piotti, P., et al. (1985) Prognosis of Breast Cancer Patients after Mastectomy and Dissection of Internal Mammary Nodes. Annals of Surgery, 202, 702-707. https://doi.org/10.1097/00000658-198512000-00007

[12] Bjstr Galecki, J., Hicer Grzenkowicz, J., Grudzien Kowalska, M., Michalska, T. and Zalucki, W. (2006) Radiation-Induced Brachial Plexopathy and Hypofractionated Regimens in Adjuvant Irradiation of Patients with Breast Cancer-A Review. Acta Oncologica, 45, 280-284. https://doi.org/10.1080/02841860500371907

[13] Owen, J.R., Ashton, A., Bliss, J.M., Homewood, J., Harper, C., Hanson, J., Haviland, J., Bentzen, S.M. and Yarnold, J.R. (2006) Effect of Radiotherapy Fraction Size on Tumour Control in Patients with Early-Stage Breast Cancer after Local Tumour Excision: Long-Term Results of a Randomised Trial. The Lancet Oncology, 7, 467-471. https://doi.org/10.1016/S1470-2045(06)70699-4

[14] Whelan, T., MacKenzie, R., Julian, J., Levine, M., Shelley, W., Grimard, L., Lada, B., Lukka, H., Perera, F., Fyles, A., Laukkanen, E., Gulavita, S., Benk, V. and Szechtman, B. (2002) Randomized Trial of Breast Irradiation Schedules after Lumpectomy for Women with Lymph Node-Negative Breast Cancer. Journal of the National Cancer Institute, 94, 1143-1150. https://doi.org/10.1093/jnci/94.15.1143

[15] Tjessem, K.H., Johansen, S., Malinen, E., Reinertsen, K.V., Danielsen, T., Fossa, S.D. and Fossa, A. (2013) Long-Term Cardiac Mortality after Hypofractionated Radiation Therapy in Breast Cancer. International Journal of Radiation Oncology, Biology, Physics, 87, 337-343. https://doi.org/10.1016/j.ijrobp.2013.05.038

[16] Yang, T.J. and Ho, A.Y. (2013) Radiation Therapy in the Management of Breast Cancer. Surgical Clinics of North America, 93, 455-471. https://doi.org/10.1016/j.suc.2013.01.002

[17] Smith, B.D., Bentzen, S.M., Correa, C.R., Hahn, C.A., Hardenbergh, P.H., Ibbott, G.S., McCormick, B., McQueen, J.R., Pierce, L.J., Powell, S.N., Recht, A., Taghian, A.G., Vicini, F.A., White, J.R. and Haffty, B.G. (2011) Fractionation for Whole Breast Irradiation: An American Society for Radiation Oncology (ASTRO) Evidence-Based Guideline. International Journal of Radiation Oncology, Biology, Physics, 81, 59-68. https://doi.org/10.1016/j.ijrobp.2010.04.042 
[18] Ciammella, P., Podgornii, A., Galeandro, M., Micera, R., Ramundo, D., Palmieri, T., Cagni, E. and Iotti, C. (2014) Toxicity and Cosmetic Outcome of Hypofractionated Whole-Breast Radiotherapy: Predictive Clinical and Dosimetric Factors. Radiation Oncology, 9, 97. https://doi.org/10.1186/1748-717X-9-97

[19] Yarnold, J., Ashton, A., Bliss, J., Homewood, J., Harper, C., Hanson, J., Haviland, J., Bentzen, S. and Owen, R. (2005) Fractionation Sensitivity and Dose Response of Late Adverse Effects in the Breast after Radiotherapy for Early Breast Cancer: Long-Term Results of a Randomised Trial. Radiotherapy and Oncology, 75, 9-17. https://doi.org/10.1016/j.radonc.2005.01.005

[20] Ragaz, J., Jackson, S.M., Le, N., Plenderleith, I.H., Spinelli, J.J., Basco, V.E., Wilson, K.S., Knowling, M.A., Coppin, C.M., Paradis, M., Coldman, A.J. and Olivotto, I.A. (1997) Adjuvant Radiotherapy and Chemotherapy in Node-Positive Premenopausal Women with Breast Cancer. The New England Journal of Medicine, 337, 956-962. https://doi.org/10.1056/NEJM199710023371402

[21] Shaltout, E.A. and El Razek, A. (2012) Adjuvant Postmastectomy Hypofractionated Radiotherapy in Egyptian Cancer Patients: A 2 Years Follow-Up. Annals of Oncology, 23, 34-36.

[22] Eldeep, H., Awad, I. and Elhanafy, O. (2012) Hypofractionation in Post-Mastectomy Breast Cancer Patients: Seven-Year Follow-Up. Medical Oncology, 29, 2570-2576. https://doi.org/10.1007/s12032-012-0192-1

[23] El-Sayed, M. and Abdel-Wanis, M.E. (2012) Comparison of Hypofractionated and Conventional Radiotherapy Protocols in Breast Cancer Patients: A Retrospective Study. Journal of Cancer Science and Therapy, 4, 158-163. https://doi.org/10.4172/1948-5956.1000132

[24] Kumbhaj, P., Sharma, R., Saini, P. and Patel, P. (2013) A Study of Two Different Dose Fractionation Schedules of Post Mastectomy Chest Wall Irradiation in Carcinoma Breast Patients. International Journal of Medical Science and Public Health, 2, 1001-1005. https://doi.org/10.5455/ijmsph.2013.040820131

[25] Ali, E.M. and Abd Al Mageed, M.K. (2014) Post-Mastectomy Hypofractionation Radiotherapy in Breast Cancer Patients. Cancer and Oncology Research, 2, 87-93. http://www.hrpub.org

[26] Pinitpatcharalert, A., Chitapanarux, I., Euathrongchit, J., Tharavichitkul, E., Sukthomya, V. and Lorvidhaya, V. (2011) A Retrospective Study Comparing Hypofractionated Radiotherapy and Conventional Radiotherapy in Postmastectomy Breast Cancer. Journal of the Medical Association of Thailand, 94, S94-S102.

[27] Singh, K., Kolse, A., Nikam, B., Kharde, R. and Nagshet, S. (2014) Result and Outcome of Shorter Fractionation Schedule for Post-Operative Cancer Breast Patients. International Journal of Research in Medical Sciences, 2, 536-540. https://doi.org/10.5455/2320-6012.ijrms20140532

[28] Doré, M., Cutuli, B., Cellier, P., Campion, L. and Le Blanc, M. (2015) Hypofractionated Irradiation in Elderly Patients with Breast Cancer after Breast Conserving Surgery and Mastectomy: Analysis of 205 Cases. Radiation Oncology, 10, 161. https://doi.org/10.1186/s13014-015-0448-y

[29] Deshmukh, S., Sharan, K., Fernandes, J.D., Srinivasa, M.V., Yathiraj, H.P., Singh, A. and Reddy, A. (2016) A Study on Dosimetric Outcomes and Acute Toxicity of Post Mastectomy Adjuvant Hypofractionated Radiotherapy for Breast Cancer. Journal of Clinical and Diagnostic Research, 10, XC05-XC08.

[30] Lori, J. (2015) Increasing the Use of Hypofractionated Radiation in Early-Stage Breast Cancer: The Way Forward. 
[31] Khan, M., Siddiqui, S.A., Gupta, M.K., Seam, R.K. and Gupta, M. (2017) Normal Tissue Complications Following Hypofractionated Chest Wall Radiotherapy in Breast Cancer Patients and Their Correlation with Patient, Tumor, and Treatment Characteristics. Indian Journal of Medical \& Paediatric Oncology, 38, 121-127. 